\title{
Active labor market policies
}

\author{
Bruno Crépon \\ Gerard J. van den Berg
}


The Institute for Evaluation of Labour Market and Education Policy (IFAU) is a research institute under the Swedish Ministry of Employment, situated in Uppsala. IFAU's objective is to promote, support and carry out scientific evaluations. The assignment includes: the effects of labour market and educational policies, studies of the functioning of the labour market and the labour market effects of social insurance policies. IFAU shall also disseminate its results so that they become accessible to different interested parties in Sweden and abroad.

Papers published in the Working Paper Series should, according to the IFAU policy, have been discussed at seminars held at IFAU and at least one other academic forum, and have been read by one external and one internal referee. They need not, however, have undergone the standard scrutiny for publication in a scientific journal. The purpose of the Working Paper Series is to provide a factual basis for public policy and the public policy discussion.

More information about IFAU and the institute's publications can be found on the website www.ifau.se

ISSN 1651-1166 


\title{
Active labor market policies ${ }^{\mathrm{a}}$
}

\author{
by \\ Bruno Crépon ${ }^{\mathrm{b}}$ and Gerard J. van den Berg ${ }^{\mathrm{c}}$ \\ $26^{\text {th }}$ October, 2016
}

\begin{abstract}
Active labor market policies are massively used with the objective being to improve labor market outcomes of individuals out of work. Many observational evaluation studies have been published. In this review, we critically assess policy effectiveness. We emphasize insights from recent randomized controlled trials. In addition, we examine policy effects that have not been the primary object of most of the past evaluations, such as anticipatory effects of advance knowledge of future treatments and equilibrium effects, and we discuss the actual implementation of policies. We discuss the importance of heterogeneity of programs and effects and examine the extent to which potential participants are interested in enrollment. We also discuss the assessment of costs and benefits of programs.
\end{abstract}

Keywords: active labor market program; evaluation; job search assistance; matching; subsidized jobs; training; unemployment; wages

JEL-codes: J08, J64

\footnotetext{
${ }^{a}$ We thank participants at the IZA Policy Evaluation Conference 2015, especially Jeffrey Smith, for feedback. We also thank Anders Forslund, Helène Turon, Annette Bergemann, and Arne Uhlendorff for helpful comments and Anna Hammerschmid and Gabrielle Varro for their assistance. Gerard van den Berg thanks the Humboldt Foundation for financial support. Posted with permission from the Annual Review of Economics, Volume 8 (c) 2016 by Annual Reviews, http://www.annualreviews.org. When citing this paper, please follow doi: 10.1146/annurev-economics080614-115738. Any opinions expressed in the paper are those of the authors; they do not necessarily represent the views or conclusions of IFAU.

${ }^{\mathrm{b}}$ Center for Research in Economics and Statistics (CREST), 92245 Malakoff, France; IZA; CEPR; Abdul Latif Jameel Poverty Action Lab (J-PAL), Cambridge, Massachusetts 02142, USA. E-mail: bruno.crepon@ensae.fr

' Department of Economics, University of Bristol; IFAU, Uppsala; IZA; ZEW; CEPR; Abdul Latif Jameel Poverty Action Lab (J-PAL), Cambridge, Massachusetts 02142, USA.
} 


\section{Table of contents}

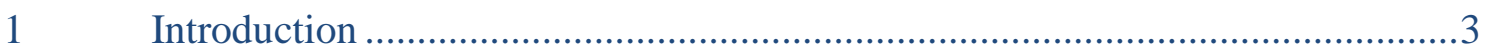

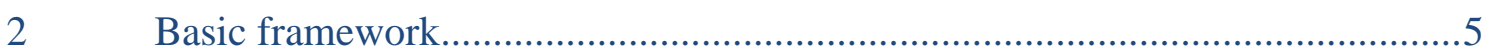

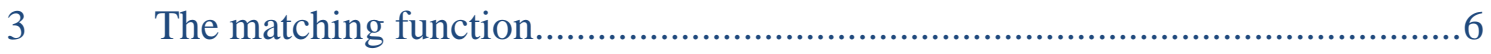

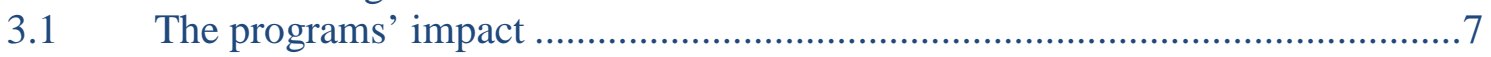

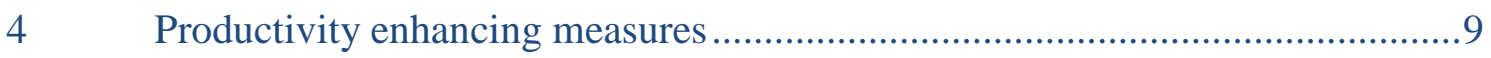

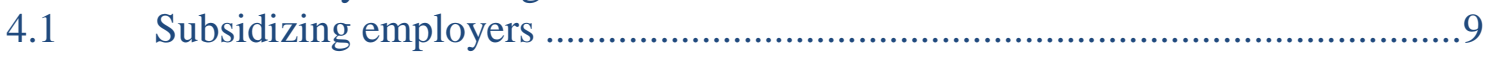

4.2 The moderate impact of employment subsidies .............................................. 10

4.3 Subsidizing job seekers' return into employment ..........................................11

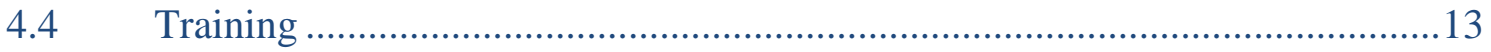

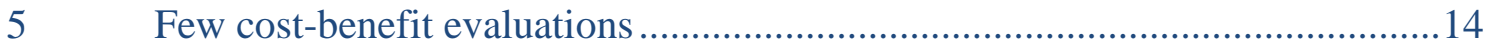

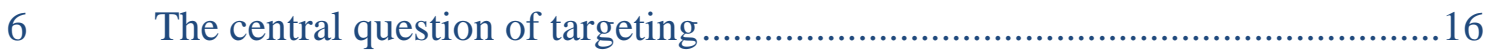

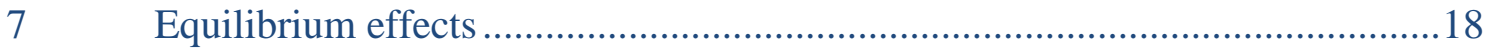

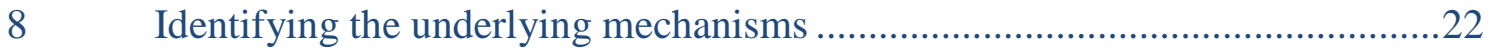

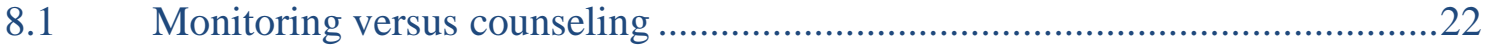

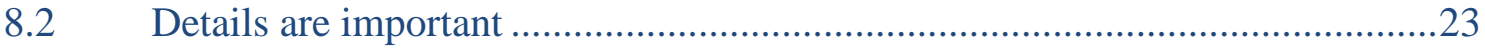

8.3 The role of information on job market opportunities ......................................24

8.4 Signaling, or gains in productivity for programs of employment subsidies .....25

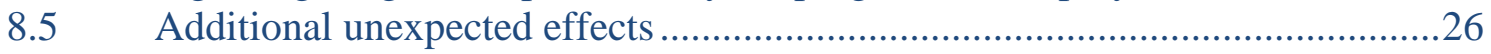

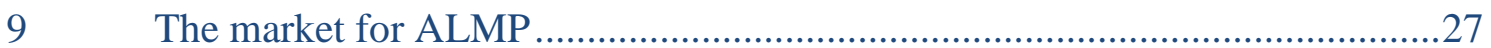

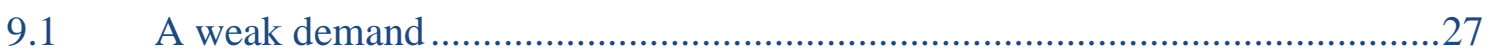

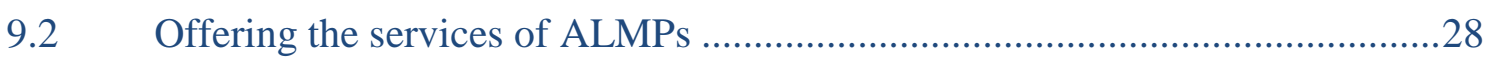

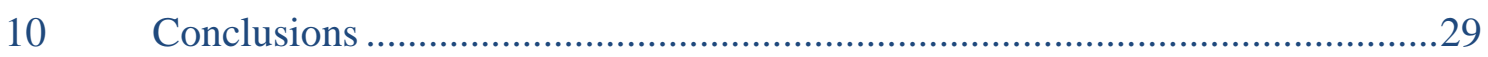

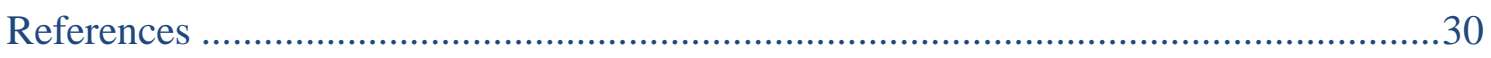

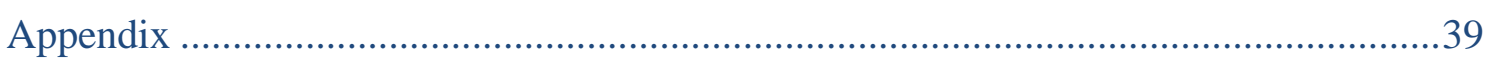




\section{Introduction}

Active labor market policies (ALMPs) are massively used to improve labor market outcomes of individuals out of work. Table 1 (Appendix) lists the percentage of Gross Domestic Product that is allocated toward ALMPs in various OECD countries in 2011 (see OECD 2013). In addition, it lists the fraction of the labor force enrolled in ALMP programs in 2011. These programs include job search assistance measures, training programs, and subsidized jobs. Unemployment benefits, youth apprenticeships, and adult education measures are excluded. As is clear from the table, there is substantial variation across countries, and some of this reflects variation in institutional designs and in definitions of what constitutes an ALMP and what constitutes ALMP participation or exposure (for details, see Grubb \& Puymoyen 2008). However, it is clear that ALMPs take up a substantial fraction of public expenditure and that sizeable fractions of unemployed individuals are enrolled at some point in their spell out of work.

During the past decades, studies have been published in which specific programs were evaluated. The prototype evaluation study uses individual-level observational data to compare labor market outcomes of ALMP participants (or those treated) to nonparticipants (or controls), in order to assess the effectiveness of ALMP participation. Many surveys and overviews have been published in which the available empirical evidence is summarized (see, e.g., Bergemann \& Van den Berg 2008, Carcillo \& Grubb 2006, Card et al. 2010, Fay 1996, Heckman et al. 1999, and Martin \& Grubb 2001). Aggregating over all the findings, it seems that job search assistance measures have somewhat positive effects on the probability of becoming employed, whereas the evidence for positive effects of training is rather slim. Subsidized jobs seem to have positive effects, but it is generally acknowledged that this measure is costly and may have negative crowding-out effects on other individuals.

In this review article, we reconsider where we stand in terms of our knowledge on ALMP effectiveness. We discuss recent insights from experimental evaluation studies. Recent studies have also examined policy effects that are not straightforward treatment effects on individual outcomes but rather side effects or external effects, such as anticipatory effects of advance knowledge of future treatments and equilibrium effects. We also discuss recent evidence on the discretionary role of case workers. We highlight the need for cost-benefit analysis, and we discuss the issue of how to choose the appropriate target population for a program. In addition, we examine the relatively scarce evidence on the pathway from ALMP to individual effect. Notably, to what extent does ALMP participation affect the attitudes of unemployed individuals and how does this affect their labor market behavior? 
Throughout the article, we use a dynamic perspective. That is, we acknowledge that individuals who are not treated today may be treated later, and that certain postunemployment outcomes can only be observed if other outcomes (notably, a transition into employment) have been realized. A dynamic perspective enables the distinction between ex ante and ex post effects as well as the discussion of lock-in effects; definitions are given in Section 2, where we outline the basic economic framework around which various possible program effects are discussed.

Throughout the article, we structure the discussion of empirical evidence on ALMP effects along the lines of the primary intention of the ALMP program. The basic distinction is between ALMPs that are supposed to improve the individual matching process and ALMPs that are supposed to improve individual productivity. Roughly speaking, the former constitute job search assistance programs whereas the latter include training programs and workfare and subsidized work. In Section 3, we examine matching ALMPs in detail, and in Section 4 we focus on productivity ALMPs. (Of course, with equilibrium effects, this distinction is blurred.) A third type of ALMP is aimed at improving the knowledge of the worker about his or her labor market conditions, either concerning matching or concerning productivity. Here, we do not mean the knowledge about the whereabouts and properties of a specific vacancy but rather the knowledge about the actual range of opportunities. It has been argued that displaced workers may have an unusually rosy view of their market value and hence tend to reject too many offers. We discuss this briefly in Section 2.

Nowadays, many non-employed individuals are effectively at a great distance from the labor market, in that they have accommodated to a life without regular work and they experience very long spells of joblessness. Among groups of young, elderly, and low-skilled individuals, median durations of joblessness can be as high as seven years. These individuals may feel rejected by society and subsequently reject society in turn. Helping such individuals may require innovative policy measures and a focus on intermediate outcomes on the pathway toward regular work. After all, if the monthly transition rate to work equals approximately 1 percent an ALMP-induced increase by 10 percent does not translate into a large number of job acceptances. Moreover, it will not affect the tendency to feel excluded from society. Therefore, it may be more sensible to focus on programs that boost self-esteem and other personality traits, as these may foster reintegration into society, which in turn may be necessary to obtain gainful regular employment. Traditional ALMPs may be ill-designed for this, and one may consider alternatives such as mentoring, therapy, and group treatments 
in which similarly disadvantaged individuals may stimulate each other. Throughout the review, we pay attention to such novel types of ALMPs aimed at disadvantaged individuals.

After Section 4, the review is structured along the lines of a number of issues that we view as pressing for future research. In each case, we summarize the available evidence and outline gaps in our knowledge of program effects. Section 5 discusses cost-benefit analysis, and Section 6 addresses the choice of target populations. In Section 7, we examine equilibrium effects, and in Section 8 we discuss the underlying mechanisms of ALMP effects. Section 9 examines the demand and supply for programs and program participation. Here, we return to the issue of ex ante program effects of individuals not yet treated (defined in Section 2), as these effects may involve attempts to prevent program participation either by leaving unemployment before the treatment starts or by influencing the treatment rate. Section 10 concludes.

\section{Basic framework}

It is useful to think of ALMPs as opportunities, or treatments, for unemployed individuals who search for jobs in a labor market with informational (or search) frictions. The literature (mentioned below) provides examples of job search models with ALMP, that can be used to examine comparative-statics ALMP effects. Here, we merely mention that the signs of the effects are often not unambiguous. Often, the advantage of participation is mitigated by an increase among treated unemployed workers in the degree that they are selective with respect to job offers. Moreover, each of the usual outcome measures (unemployment duration, postunemployment wage, etc.) taken separately only captures part of the total effect on the expected present value.

The current review pays particular attention to so-called ex ante program effects (see, e.g., Abbring \& Van den Berg 2003). The prospect of a future beneficial treatment causes the individual to be more selective regarding job offers before the treatment takes place, compared to a setting in which the program does not exist. Likewise, the prospect of an unpleasant treatment creates an incentive to leave unemployment before the treatment. Ex ante effects can be contrasted to the treatment effects relative to the pretreatment situation; the latter effects could therefore be called ex post treatment effects. It matters which comparison group is used to evaluate treatment effects. If the comparison group is observed in a period in which the program was absent, then the counterfactual outcomes for the treated differ from the case where the comparison group consists of the not-yet-treated in a market 
where the program exists. The former approach is in line with regression discontinuity designs. The latter approach is in line with dynamic matching (see, e.g., Vikström 2014), and with the timing-of-events evaluation method (Abbring \& Van den Berg 2003). Notice that in these cases, determinants of the treatment rate affect the outcome before the treatment is realized, thus violating any exclusion restriction for those determinants as potential instrumental variables for the treatment effect.

It has been recognized in the literature that being enrolled in an ALMP program may be disliked by participants despite any positive effects of program participation on the job search process and/or on productivity (Van den Berg, Bergemann \& Caliendo 2009). The ex ante effect of a treatment may then reflect both the threat of participation and the future benefits incurred from a treatment. Indeed, threat effects may dominate the total ex ante effects of training. Effectively, the threat of participation then drives people out of unemployment into low-paid jobs before the actual program participation. As a side effect, the number of actual participants will be reduced.

In reality, treatments take time away from other activities. This is especially true for productivity-enhancing treatments like vocational training. These time costs are made up front and may annihilate any positive effect of the treatment on the mean unemployment duration. The effect of these time costs is called the lock-in effect.

A rather novel type of ALMP is aimed at improving the knowledge of the worker about his or her labor market conditions, either concerning matching or concerning productivity. This may be relevant for a range of different unemployed workers. Displaced workers may have an unrealistically rosy view of their chances in the labor market, and a signal about their actual chances may act as a wake-up call for them to reconsider their search strategy (see, e.g., Van den Berg \& Vikström 2014). Alternatively, many unemployed workers may not be aware of the extent of variation in wage offers in their occupation. By incorporating information on wage offers from other occupations, they may overestimate the variance of their relevant wage offer distribution $F$. Ex ante effects are less natural in this case because if individuals assume that there is a rate at which the knowledge about the shape of $F$ will be updated in the future, then they have an incentive to obtain that information immediately.

\section{The matching function}

There are several types of programs devoted to matching job seekers with job vacancies. Their purpose is to speed up the return to employment and enhance the quality of new jobs. 
First, there are the services aimed at improving the techniques of the job search. During their search, job seekers may encounter personal difficulties or have difficulties finding information about the labor market. They can use the services set up to assist them in their job search and receive training on how to use them by meeting with a counselor. Sometimes, this involves only a workshop lasting a few hours, but it can also involve regular meetings over long periods. The intensity of the assistance received is linked to the number and frequency of the appointments. Sometimes, these services also provide direct job search assistance and involve direct matches of job seekers with existing vacancies. Nevertheless, such assistance does not always come alone. Sometimes it is accompanied by an element of monitoring of the job seeker's efforts to find work. Appointments between counselor and job seeker also serve to check if the latter is trying hard enough; active job search is a prerequisite for the benefits that job seekers receive. Monitoring involves the threat of sanctions. These may be triggered by a missed appointment, by an effort considered lackadaisical (such as a low rate of applications), or by yet again rejecting a job offer the counselor deemed acceptable.

\subsection{The programs' impact}

Job search assistance services have been assessed on many occasions and their impact is well known today. Globally, results show that the impact on the return to employment is positive. The meta-analyses by Card et al. (2010, 2015), reviewing evaluations carried out since 1997, reveal a general tendency in favor of job seekers' return to employment. Most studies focus on employment outcome.

Blundell et al. (2004), for example, looked at the New Deal for Young People program in the United Kingdom. A first phase lasts four months and commences upon an elapsed period of unemployment of six months. During this initial phase, recipients are given intensive assistance in the job search, that is, an appointment with a counselor every two weeks. ${ }^{1}$ The program is aimed at 18- to 24-year-olds and was first implemented as a pilot in a few regions. This sort of configuration generates the exclusion of a portion of the job seekers per region or per age group, which taken together with the date the program was initiated makes it possible to identify its impact. The authors compared the probability of the young beneficiaries moving into employment after the four-month phase with that of a control group, using the difference-in-difference method. They found that the program improved beneficiaries' chances of moving into work by 5 percentage points with a baseline transition probability of

\footnotetext{
${ }^{1}$ After the four-month period, those participating in the program who were still jobless were offered various options: a subsidized job in the private or public sector, or training.
} 
26 percent. Many evaluations were also carried out using randomized experiments. Meyer (1995) reports the results of several randomized evaluations in the United States that showed that all job search assistance programs reduce the period during which job seekers can claim unemployment benefits.

It is difficult to distinguish in these evaluations what concerns job search assistance and what concerns the monitoring of job seekers' efforts, a question to which we shall return. Effects of punitive sanctions have been studied since the work of Van den Berg et al. (2004). The empirical literature invariably finds that sanctions increase the reemployment rate, sometimes stretching beyond the period in which benefits are reduced, which suggests that the punished individuals are subject to intensified monitoring after the violation. ${ }^{2}$

Available studies on the impact of matching services most often examine effects in the short and medium run, rarely exceeding one year. Dolton \& O’Neill (2002) is a rare exception. It examines the long-term impact of programs. Their conclusion is that it confers a lasting gain in terms of the unemployment rate over a five-year period for male beneficiaries.

A side objective of job search assistance is to enhance the quality of the newfound jobs. Fewer results are available concerning the impact of assistance programs on that count; ${ }^{3}$ indeed, measuring such an impact is difficult on a conceptual level. Even when one starts out with a random evaluation, comparing newly found jobs in a finite observation window is tricky, as the interventions under consideration generally have an impact on entry into employment itself (see Ham \& LaLonde 1996). This led D.S. Lee (2009) to propose bounds on the effect of the programs. As proposed by Ham \& LaLonde (1996), an alternative consists in modeling the heterogeneity within a duration model. In a randomized evaluation of an assistance program in Denmark, Blasco \& Rosholm (2011) show that the stability of newly found jobs improves for those who participated in the program (for an observational study, see Crépon et al. 2005). Van den Berg \& Van der Klaauw (2013) combine a randomized controlled trial with a structural analysis and find that wages are lower among those who were monitored more intensively.

\footnotetext{
${ }^{2}$ Some evaluations on job search assistance and monitoring were carried out within the framework of controlled experiments; Van den Berg \& Van der Klaauw (2006) provide an overview and Behaghel et al. (2014) a recent evaluation. All of these evaluations found positive effects on the transition into employment although the effects are sometimes not significantly different from zero and may depend on labor market conditions.

${ }^{3}$ Studies conducted in Europe have most often dealt with the rate of return to employment. Few of them bear on the number of days worked or on the different types of revenue paid out over a particular period.
} 


\section{$4 \quad$ Productivity enhancing measures}

A different type of ALMP programs aims at improving job seekers' productivities and wages. Textbook examples of this are skill-enhancing training programs. The distinction between the types of interventions discussed in the previous section and the productivity-enhancing interventions of the current section is often motivated by the difference between giving priority to accessing employment and giving priority to skill acquisition. For convenience the current section also includes a discussion of employment subsidies and subsidized jobs. Subsidized employment is sometimes called on-the-job training. Admittedly, this is somewhat misleading. After all, many nonsubsidized jobs also involve training, whereas subsidized work does not necessarily involve skill accumulation. Indeed, a subsidy may simply make an employer willing to take the risk to hire a long-term unemployed who may (or may not) have a low productivity.

\subsection{Subsidizing employers}

Although the idea of employment subsidies is simple, a salient factor is the great variety of forms such programs can take. They may mean a direct transfer to or a tax rebate for the employer or also payroll tax subsidies for low-wage workers. Subsidies can be applied to the entire category of employees concerned or only to newly minted jobs. Subsidy schemes can therefore become rather intricate. Certain interventions also take the form of vouchers attributed to the eligible public, who hand them over to the potential employer, who in turn must claim his or her rights in order to actually pocket the subsidy. In the case of the Job Training Partnership Act (JTPA) of 1982, firms had to employ the beneficiary for a certain amount of time to avoid the risk of becoming ineligible for further subsidies (see Katz 1998). In other cases, firms create positions specifically for the people targeted by a subsidy. These systems usually target specific populations. Targeting generally means combining a criterion linked to the technology of production (e.g., low-skilled workers) and a social criterion (e.g., young people with social integration problems, or the long-term unemployed). ${ }^{4}$ The rate of subsidies may vary as well as the length of contracts: Caliendo et al. (2005) quote subsidy rates that vary from 30 to 75 percent of the total cost and periods that vary from 6 to 12 months. All told, the programs provide a rather complex set of incentives for the firms and the beneficiaries and are the outcomes of processes that are also complex and heterogeneous. We have little information on how the details of a program affect its implementation and how

\footnotetext{
${ }^{4}$ Many programs evaluated in the United States concern marginal groups such as populations who have received social benefits over long periods, people suffering from depression, former inmates (see Butler et al. 2012).
} 
beneficiaries enter it in the first place. Several studies mention a very low take-up rate: Many filled jobs generate a bonus for the employers, but they never claim it. ${ }^{5}$

\subsection{The moderate impact of employment subsidies}

Many studies have dealt with the impact of employer-based employment subsidies on labor market outcomes for job seekers. From the overviews and meta-analyses carried out by (Card et al. 2010, 2015), it appears that employment subsidies constitute a moderately effective policy. Overall, they seem to have an impact while job seekers are in the program, but that employment effect fades quickly after the subsidized contract ends. On one side, there are a great many studies in Europe, most often bearing on periods of employment and unemployment and often based on administrative databases listing the types of employment experienced. Here, again, it is worth noting that most studies have focused on employment rates. Results are typically obtained using matching methods. ${ }^{6}$ On the other side, an abundant literature exists in North America based on research most often carried out by large, nonacademic research institutes in response to official directives. These studies frequently use randomized evaluations and place the accent on employment but also on the various types of earnings. The National Supported Work Demonstration (NSWD) project is an example of such programs. It consisted of subsidizing paid work experience in the United States for a maximum length of 18 months. Hollister et al. (1984) present results over the first three years of the program. It shows a positive and durable impact on jobs, schedules, income, and global revenue as well as a drop in transfer revenue. The seniority of these experimental programs makes it possible to examine their impact over the long term. Couch (1992) examines the impact on income after eight years and shows a positive and significant impact for women receiving benefits as a result of Aid to Families with Dependent Children (AFDC) during the first eight years - that is, an overall rise of \$ 2,728 since 1978. The type of employer involved may vary substantially across programs. One important issue concerns the difference between subsidized jobs in the private and public sectors (including, broadly speaking, volunteer and nonprofit associations). The studies available almost unanimously show that subsidized employment in the public sector has less impact than in the private sector; ${ }^{7}$ this is particularly

\footnotetext{
${ }^{5}$ Katz (1998) discusses such programs in the United States and Galasso et al. (2004) as well as Levinsohn et al. (2014) discuss programs based on vouchers in South Africa.

${ }^{6}$ These methods are implicitly based on a static underlying model and are not well adapted to the analysis of the process of dynamic assignment (see Abbring \& Van den Berg 2005, Abbring \& Heckman 2007, Crépon et al. 2009, and Vikström 2014).

${ }^{7}$ For example, Caliendo et al. (2005), Brodaty et al. (2002), and Gerfin et al. (2005) simultaneously evaluate both types of programs Bloom (2010) provides information on so-called transitional jobs.
} 
true of long-term impacts, which totally disappear. ${ }^{8}$ However, a complicating factor in such a comparison is that job seekers are usually quite different between the two sectors. The population assigned to subsidized jobs in the public sector has usually been excluded from the regular labor market for some time (although some large programs in Europe aim at creating jobs for broad categories of job seekers, such as the young). There is an important aspect of self-selection present in these programs. Although no studies exist on such a topic, it might be possible that most job seekers who take a subsidized job in the private sector would turn down an offer of a subsidized job in the public sector. Intermediate outcome variables, however, are likely to be affected by participation in subsidized labor: self-esteem and mental health, family stability, children's education. On a different score, employment subsidies do not aim exclusively to improve the trade-off between employment and the job search. Sometimes, they also aim to improve the trade-off between active and nonactive status. By offering short-term employment and increasing the perceived chances of getting a well-paid job later, they allow some to remain active in the labor market. Employment subsidies are therefore sometimes a way of staving off criminality or violence, a threat that occurs particularly in post-conflict situations in developing countries, where many young people affected by war remain jobless in an environment still marked by potential violence. This is equally the case for employment programs directly aimed at former prisoners with the objective of avoiding a repeated offense. We have little information on these elements. Large demonstration projects in the United States, however, frequently report results along these lines. Bloom (2010), for example, reports negative impacts on criminality among certain categories of beneficiaries (particularly former drug addicts in the NSWD project) and positive impacts on children's education. In our view, this is an area in which further research is warranted.

\subsection{Subsidizing job seekers' return into employment}

A subsidy for job seekers who take a new job constitutes another type of employment subsidy program. These have also been widely studied. Several types exist: a bonus for reemployment that allocates a lump sum if the job seeker finds a job in a given lapse of time, or negative taxation consisting of a transfer of income earned from employment. The Earned Income Tax Credit (EITC) was a pioneering scheme, and many countries have progressively adopted systems based on the same make-work-pay principle.

\footnotetext{
${ }^{8}$ Some studies even report negative impacts in the long term, but these are based on matching methods. The fact that this population had spent a long time excluded from the job market, with many specific unobservable characteristics, casts doubt on the usefulness of such methods in such a context.
} 
Reemployment bonuses have been evaluated several times, including by Meyer (1995). These programs consist of awarding a bonus approximately equivalent to several weeks of transfers. Results have shown that beneficiaries exited unemployment more rapidly - three to seven days earlier - and above all that the savings realized in terms of benefits were greater than the dollar amount of bonuses paid out.

Negative taxes also have been evaluated. Using the difference-in-difference method, for example, Eissa \& Liebman (1996) showed that in the United States, the EITC had a positive impact of 4 percentage points on the return to employment for single women with children. ${ }^{9}$

The Self-Sufficiency Project (SSP) in Canada proposed another transfer mechanism consisting of awarding a three-year bonus depending on the employment situation (working at least 30 hours a week). Job seekers who had received welfare benefits for at least one year were eligible. Card \& Hyslop (2005) evaluated this program using a randomized control trial and showed that the program had a large initial impact on employment that diminished little by little and disappeared after four years. ${ }^{10}$ Studying the income of this same program over the first three years of its implementation, Michalopoulos et al. (2005) showed that the system greatly improved beneficiaries' income. Earnings in particular increased considerably, whereas the income from transfers increased only marginally. The authors also showed that gains in terms of taxes linked to the progression of labor market earnings largely exceeded the extra transfer income.

Normally, subsidizing job seekers who find a new job (i.e., the supply) or firms when they take on the job seeker (i.e., the demand) should amount to the same thing, if the wages offered and demanded are flexible enough to adjust to the subsidy schemes. Nevertheless, when salaries are not flexible, as is the case for employees whose productivity is close to the minimum wage, for example, adjustments cannot take place and the two modes of subsidy diverge. Although not recent, the study by Woodbury \& Spiegelman (1987) is typical of what randomized controlled trials can potentially contribute to our knowledge of the mechanisms underlying the programs. They tested the two systems simultaneously through an experiment in which beneficiaries were assigned at random to a control group or to one of two treatment groups. In the first treatment group, beneficiaries received a voucher entitling them to a bonus if they were reemployed and in the second group a voucher to give the potential employer, who in turn would be entitled to a bonus of the same amount in the case of employment.

\footnotetext{
${ }^{9}$ There is also much literature (that we cannot address here) on the impact of program incentives on the number of hours of work.

${ }^{10}$ They also showed that beneficiaries respond eagerly to the incentive to return to employment as eligibility for a transfer depends on finding a new job in the first 12 months.
} 
Results showed that giving the bonus to the job seekers had a positive effect on the return to employment, whereas giving it to a firm in this case did not.

\subsection{Training}

Training is the cornerstone of active labor market policy. Expectations surrounding the potential of training to give access to employment and lead to better-quality jobs are enormous. There is considerable variety in the systems that are supposed to provide training. Training programs differ in the priority given to acquiring a general education, to acquiring skills, to the distinction between soft and hard skills, and to the type of apprenticeship, whether in the classroom, on the job, or alternating. They differ also by the investment they represent in terms of money or time. Lechner et al. (2011) define a short training period as lasting less than six months, and a long one as lasting more. The incentive for training is also likely to be very different depending on the individual. Training may be meant to consolidate a skill, improve it, or reorient it.

Much literature exists on the impact of such training programs. Card et al. (2010, 2015) show that on the whole, they have small or even negative impacts in the short run but that this improves over time and impacts become positive or even substantial and significant in the long run. Bergemann \& Van den Berg (2008) were the first to provide a large-scale overview of evaluation results (for all ALMP types) by gender. They find that effects are greater for women than for men, and that the difference is larger if the economy has many unemployed women. Apparently, the larger the latter fraction, the higher the potential for programs that update the women's skills.

Lechner et al. (2011) analyzed the impact of training programs in Germany. Their study was based on matching methods and programs that were divided according to duration (long, short, retraining, based on simulations in real-world work contexts); its special feature was that it followed job seekers over an eight-year period. Results showed considerable long-term impact on employment situations for all types of training programs: approximately 10 percentage points for short or long training programs and approximately 20 percentage points for retraining. Also, positive effects appear quite rapidly: within 6 months for the short and 12 months for the long training periods, and much later (24 months) for retraining programs. 
Several evaluations were based on randomized experiments, mainly in the United States. ${ }^{11}$ Bloom et al. (1997), for example, evaluated the JTPA and found positive impacts on income cumulated over 30 months, mainly for women. One persistent feature seems to be the absence of results for young job seekers. Yet, it is on them, particularly on the unskilled among them, that a good deal of the expectations in matters of training are placed. Very intensive programs could have positive impacts. The Job Corps program first places its young participants in a residence under strict surveillance. They are given a general education, professional training, health education, and courses in social skills. At the end of the first phase, beneficiaries receive job placement services. The program was evaluated through a large-scale experiment that included up to 15,000 young people (Schochet et al. 2008). Its impact on the acquisition of general education and professional skills was very positive. Impact on income was initially negative for two years before becoming positive and significant for two more years and then disappearing. The impact on employment was initially strong but progressively dwindled and disappeared after four years. The authors also note a significant drop in criminality. Impacts were most significant among the oldest group (aged 20 to 24 years). ${ }^{12}$

\section{$5 \quad$ Few cost-benefit evaluations}

Meyer (1995) has developed a simple framework to conduct a cost-benefit analysis. Surprisingly, only a few evaluations have implemented such analyses. They are needed to learn more about gains in terms of benefits paid out and salaries earned by job seekers and gains in terms of social security contributions paid to the State, as well as the costs of the program. Generally speaking, evaluations carried out in North America in the form of demonstrations have been the only ones capable of mobilizing the administrative means necessary to collect the information for the cost-benefit analyses (Bell \& Orr 1994, Cave et al. 1993); however, Forslund et al. (2011) provide an analysis for a program in Sweden. Cave et al. (1993) show that the JOBSTART subsidized employment program had a weak positive

\footnotetext{
${ }^{11}$ No evaluation in Europe applied this type of method. A few studies exist on developing countries; Card et al. (2011) found no effect on employment one year after the end of the program in the Dominican Republic. Hirshleifer et al. (2014) found no impact for a professional training program in Turkey evaluated over three years on a large scale. Attanasio et al. (2011) is a notable exception: they found positive but limited impacts of professional training on young people in Colombia in the short run. Attanasio et al. 2015 and Kugler et al. 2015 have both examined impacts at 10 years on formal employment and earnings as well as on tertiary education. Results are highly encouraging, showing important impacts on earnings, larger for women. It is worth to note that the vocational training programs also includes an on the job training component and that incentives are given to the training center to improve the link with firms.

12 The Challenge program (Millenky et al. 2011) is based on a similar concept. Results after three years show that skills progress as well as employment and income, but there is no improvement on criminality.
} 
impact on total earnings for participants but led to a large increase in taxpayer expense and represented a net loss for society as a whole. ${ }^{13}$

In order to carry out such analysis, it is necessary to have access to a larger set of outcome variables - more than a person's employment status, which remains most frequently the only variable considered. Access to paid unemployment and social transfer benefits would be needed, along with wages and other earnings, social security contributions, and other taxes paid to the State, as well as the costs of the program and of the job seeker assistance. Not only do we lack information on the sorts of new jobs found by job seekers, but we also lack general information about gains for the beneficiaries. Often, existing cost-benefit analyses only consider the point of view of the government and compare the cost of the programs to gains in terms of the benefits paid out to the recipients; these gains themselves are frequently imputed (see Behaghel et al. 2014). In the end, it has not been possible to fully explore the potential of randomized evaluations to measure the impact of participation in assistance programs on the various sources of income and their contribution to overall production rates in the community. ${ }^{14}$ The information exists but is often mainly administrative and would require rather complicated and constrained matching procedures.

In general, costs are not well known either. Frequently, they are imputed. For example, in the case of assistance programs, costs may be imputed by estimating the counselor's time and hourly rate. This is a serious drawback, for knowing the cost of a program is an absolute necessity when implementing cost-effectiveness analyses, which have proved very instructive with regard to educational policies in developing countries (Dhaliwal et al. 2011). Actually, undertaking such cost-effectiveness analysis would be extremely useful. One striking point is the strong heterogeneity of programs with respect to their content or intensity. In addition to finding positive effects, it would be beneficial to have a better idea of whether or not the extent of the exposure matters. Given the strong heterogeneity of programs, this exercise is difficult, but scaling program impacts by their cost would be a nice addition in this sense.

One factor that has consistently remained on the sidelines of cost-benefit analyses is the value of services and goods produced thanks to a program, for example, when employment subsidies are involved and earnings are not observed. Subsidized jobs in the public sector are quite common in many countries, to provide an alternative and an income for very marginal

\footnotetext{
${ }^{13}$ The studies reported by Bloom \& Michalopoulos (2001) on the transitional welfare-to-work programs also report gains in terms of earnings for the beneficiaries as well as reductions in terms of transfer, but as a whole, participant income was almost unchanged.

${ }^{14}$ An exception is Van den Berg \& Van der Klaauw (2013), who observe various individual duration and wage outcomes as well as the administrative costs of a monitoring program.
} 
populations. Aside from the eventually sustainable upgrade of beneficiaries' situations, public employment produces goods whose value should be included in a cost-benefit analysis. The study by Bell \& Orr (1994) on the AFDC subsidized employment program HomemakerHome Health Aide Demonstration is one of the few to have included the value of the services produced. Similarly, subsidized employment programs in the public sector can also reduce criminality among vulnerable populations. The cost-benefit analysis of the Job Corps program (Schochet et al. 2006) accounts for the gains related to young people not being incarcerated as well as the gains for the collectivity of crimes not committed.

With large-scale training programs, an additional source of costs comes from the flow of teachers from regular education to the training program. Such programs may therefore generate negative external effects on the quality of regular education (for empirical evidence with data from Sweden, see Björklund et al. 2005).

\section{The central question of targeting}

It is not always clear what is the optimal target population of a program. It is well known that estimated impacts are often heterogeneous across subpopulations. Heckman et al. (1997) developed a method to apprehend the variability of impacts even when they are caused by unobservable factors. Their approach consists in using bounds on the joint distribution of potential outcomes based on their identifiable joint distribution. Actually, the lower bound is obtained when assuming rank preservation, an assumption that also makes it possible to interpret quantile treatment effects (the difference in quantiles of the outcome variable distribution in treatment and control groups) as treatment effects for those at a specific quantile. This is the way Bitler et al. (2006) address the impact heterogeneity issue of the Jobs First program. Using quantile treatment effects, they show how large heterogeneity can be and that behind a modest average impact, large negative and large positive impacts actually exist at various quantiles, as well as zero impact for a large range of quantiles.

Most of the results nevertheless examine variability corresponding to observable characteristics and frequently show that a good deal of variability exists. Programs sometimes target a particular population, but often they are open to a broad eligible population. Their impact in this case can be different depending on the characteristics of the beneficiaries. A particularly important heterogeneous dimension is that linked to age: Few assistance programs prove effective for young people. Bergemann \& Van den Berg (2008) in particular bring to light a strong degree of variability across gender. Behaghel et al. (2014) show that 
the impact of the program of reinforced assistance they looked at varies significantly according to the degree of employability of the beneficiaries. These observable characteristics, however, do not account for impact variability: Djebbari \& Smith (2008) expanded methods based on Heckman et al. (1997) and showed that a large variability in impacts remains even when controlling with a large set of covariates. Some of the large programs in the United States evaluated through demonstration projects were also analyzed based on beneficiary type, often revealing a high level of variability. For example, the NSWD (Hollister et al. 1984) has been examined by specifically looking at male and female adults, young people, ex-offenders, and ex-addicts. Examining the impact of welfare-to-work transition programs, Friedlander (1988) showed that such programs had an impact, especially on beneficiaries within the eligible populations who were averagely disadvantaged but had little impact on the most disadvantaged populations. In the systematic analyses carried out by Michalopoulos \& Schwartz (2001) and Michalopoulos (2004), a high level of variability of impact was also highlighted, depending on the characteristics of the population.

Friedlander's study was influential, for it led to a rethinking of the welfare-to-work program to better meet the needs of the main population targeted by these programs, that is, the most dependent. Another implication of heterogeneous impact is the question of targeting: Who should have access to interventions? Average impacts are rather small, but there is room for potential improvement through optimized targeting. Many contributions have considered the question of allocating job seekers to programs (see, especially, Eberts et al. 2002). Driven by Manski (2004), a substantial number of econometric studies have been published concerning the question of targeting and identifying the best rules for allocation. One question, for example, is which among a set of programs (e.g., job placement, employment subsidies, and training) various categories of job seekers should be assigned to so as to optimize the average employment situation. Frölich (2008) developed a targeting method for that question aimed at maximizing the rate of return to employment. Unfortunately, there has been no implementation of such targeting devices. ${ }^{15}$ Although they were unable to precisely evaluate the gains associated with optimal targeting, Frölich et al. (2003) and Lechner \& Smith (2007) show that the assignments made by caseworkers are suboptimal on average.

A related question is who should have access to a program if the number of placements is restricted. Employment programs are frequently implemented with limited means. In the very

\footnotetext{
15 The study by Behncke et al. (2007) was an attempt, but the practical implementation of targeting turned out to be problematic.
} 
different case of the distribution of mosquito nets to prevent the spread of malaria, Bhattacharya \& Dupas (2012) consider the question of maximizing a utilitarian objective by distributing a given number of nets to a large population. The innovation with regard to the settings, developed after Manski (2004), is that a given number of mosquito nets were distributed rather than distributing nets to those for whom a positive impact was predicted. Their results are impressive. They examine the impact of a subsidy for nets and measure the impact of having a net hanging above the bed (which combines impacts of purchase and use). They consider the case where there is just enough means to give the subsidy to $50 \%$ of those eligible. They show that average impact on the population receiving a subsidy can be increased by as much as $17 \%$ compared to a situation in which subsidies are randomly allocated. However, the question of targeting cannot be addressed without having an idea of what the official authorities' objectives are: maximizing the average rate of return to employment or income, or putting the accent on job seekers who are the most excluded from employment and have the most modest income.

\section{$7 \quad$ Equilibrium effects}

Setting up a program, and the impact it has on beneficiaries, may modify their economic environment. Equilibrium effects can have several appearances. One is that nonbeneficiaries or not-yet-beneficiaries are affected after a program is set up. Another is that the impact on beneficiaries may incorporate both a direct effect of the program and an indirect effect linked to the change in environment.

In terms of a simple job search model, equilibrium effects may appear in the job offer arrival rate $\lambda$ and through the wage offer distribution $F$. We should point out that is not necessarily the case that policies acting upon the arrival rate can only have equilibrium effects working through the arrival rate. The same applies to the wage offer distribution.

Along these lines, it is possible that ALMPs aimed at the matching process have equilibrium effects that affect $F$. For example, it has been recognized that job search assistance and mobility-enhancing measures that increase $\lambda$ may cause firms in equilibrium to offer higher wages on average. Cahuc \& Le Barbanchon (2010) show, within a matching model, that for certain job seekers, an assistance program may be accompanied by a rise in salary, leading to a slower tempo of job creation. The slowdown affects the beneficiaries themselves as well as other job seekers. 
In an even more schematic case, a given number of jobs are vacant. Assisting some job seekers in their search might increase their chances but commensurately diminish those of job seekers not receiving assistance. All of the programs aimed at improving matching are vulnerable to such effects.

These effects have long been recognized as a potentially important feature of the policy of job search assistance (see, e.g., discussions in Heckman et al. 1999). ${ }^{16}$ On the empirical side, there are several challenges. Comparing beneficiaries and non-beneficiaries may be misleading, even within a randomized evaluation, if the situation of the control group is itself affected by the implementation of the program. Besides, measuring the effects on nonbeneficiaries themselves is complex. Typically, it is expected that the effect on nonbeneficiaries should be slight. That is the case, for example, when the beneficiaries are a small proportion of the eligible population. But an effect that is small at the individual level may not be negligible on a larger scale, precisely because it applies to a large population.

This challenge is particularly important when a program's aim is to improve the overall employment situation. That is the case of subsidized employment policies, whose declared aim is often to increase the overall number of jobs. Providing job seekers with employer vouchers, thus diminishing labor costs for employers hiring them, may improve their chances at finding a new job, but it can also be to the detriment of other job seekers. That will be the case particularly if firms do not create more jobs. It is commonly thought that this type of employment program lowers the marginal cost of labor and should thus create employment. Nonetheless, if there are few beneficiaries, firms should logically decide first to fill the jobs they had counted on thanks to employment subsidies, before hiring nonsubsidized workers, and it is possible that for lack of subsidized workers, the cost of these marginal jobs is not lower. In such a configuration, the overall volume of employment remains unchanged. That is why subsidized employment subsidies may miss the mark by not creating jobs despite the gain they represent for the beneficiaries.

A second challenge is extrapolating the impacts measured on the basis of experimental, small-scale projects when a program is expanded. When equilibrium effects exist, the impact on beneficiaries and nonbeneficiaries alike may vary depending on the size of the program. What can be learned by applying a program on a small scale may not correspond to the effects obtained once it is brought up to scale. Following Davidson \& Woodbury (1993), many studies have dealt with the problem of scaling. These studies consider a theoretical

\footnotetext{
${ }^{16}$ The analysis by Calmfors (1994) provides a typology of the various types of effects to take into consideration.
} 
model of the behaviors of firms, workers, job seekers, and the State and examine the impact of a program when the participating segment of the eligible population varies. Lise et al. (2015) use experimental data to calibrate a model they devised to study the impact of the SSP in Canada. These various attempts have shown that the impacts of equilibrium effects can be large and can considerably modify the way a program is considered on the basis of the results of a small-scale evaluation. These extrapolations, however, rely on a hypothetical representation of the behavior of individuals that is supposed and neither tested nor validated by direct observation. As an example, Lise et al. (2015) show that the results of a cost-benefit analysis would be reversed were the program generalized. Much empirical research has sought to directly measure the end results of programs, sometimes separating effects on beneficiaries from effects on nonbeneficiaries. The main idea is to compare two worlds in every aspect identical, one where the program is implemented and one where it is not. Several studies have followed the same tack, using a comparison of geographic regions. However, as discussed by Forslund \& Krueger (1997), public authorities have no reason to randomly choose the areas where the program is to be implemented. The comparison is therefore likely to confound equilibrium effects with the specificities of areas selected to develop the program. Several recent studies have attempted to overcome this difficulty using the same types of identification strategies as those used for the assessment of program impacts themselves. Blundell et al. (2004), in the case of the evaluation of the New Deal for Young People, use the difference-in-difference method to identify displacement effects. They use observations of eligible and noneligible individuals, before and after the implementation of the program, in regions where it was developed and in regions where it was not. They do not identify any equilibrium effect.

Ferracci et al. (2014) present an original analysis based on a double matching method whereby markets are characterized by their rate of participation. They make a double conditional independent assumption, one for the intensity of program implementation at the local level and one for individual participation in the program. The study found that a training program has a greater impact if implemented at a low-intensity level. If a program is used for a large percentage of unemployed people, then crowding out results in lower average treatment effects.

Albrecht et al. (2009) use a structural equilibrium model approach in combination with a major, nationwide skill-upgrade program in Sweden. Here, the equilibrium effects act on wages as well as job offer arrival rates. The production technology of firms is such that they respond to the increasing supply of higher-skilled workers by increasing the number of 
vacancies tailored to them. Heckman et al. (1998) offers a structural analysis with a different type of production function. In such analyses, it is important to consider that skills can also be obtained in regular education. If skills can be easily upgraded in adult education, this provides an incentive for young people to drop out of regular education and postpone further skill acquisition until later in life. It is questionable whether the latter is efficient from an economic point of view (see, e.g., Björklund et al. 2005).

Crépon et al. (2013) present an original study based on a randomized controlled trial using double randomization. ${ }^{17}$ They looked at a job search assistance program aimed at young university dropouts: They identified 235 geographic zones, akin to micro labor markets supposedly independent from one another, and in a first round of randomization, these micro markets were assigned to assign $0,25,50,75$, or 100 percent of their eligible population to the program (in a second round of randomization). The design produced two types of control groups, one so-called pure control group in zones where the program was not implemented, and one so-called competitive control group where it was (i.e., a zone with 25, 50, or 75 percent of the population assigned). Comparing the pure and competitive control groups identified displacement effects. Comparing a group assigned to the program to the pure control group identified the impact of the program. Comparing this impact with naive impact based on the traditional comparison of a treatment group to the competitive control group gives an idea of the size of potential errors when ignoring equilibrium effects. Lastly, concerning the use of different levels of assignment to the program as opposed to a fully assigned group, such a design also provides information about the effect of generalizing the program. Results show that the program had a significant and important impact on the beneficiaries but also that the totality of that effect was obtained to the detriment of nonbeneficiaries. On the whole, the program did not lead to any clear return to employment and consisted in giving a temporary advantage to participants to the detriment of the others. The authors also analyzed heterogeneous impacts and displacement effects in relation to the state of the labor market. They found that both impacts and effects of displacement are greater in weak labor markets. $^{18}$

\footnotetext{
${ }^{17}$ The idea of such a double randomization first appeared in Moffitt (2002).

${ }^{18}$ The effect of the business cycle on treatment effects is relevant for many reasons. It is during periods when the economic environment is fragile that public authorities are most inclined to intervene and finance job search assistance programs (see discussion in Card et al. 2015 and results in Forslund et al. 2011).
} 


\section{$8 \quad$ Identifying the underlying mechanisms}

ALMPs provide means for beneficiaries as well as incentives; they also demand personal investment. Most research has considered programs as a whole without being able to disentangle factors contributing to final impacts. Frequently, too, programs operate as a combination of several programs. Nonetheless, some studies do identify key elements of underlying mechanisms.

\subsection{Monitoring versus counseling}

A first question concerns job search assistance programs. These are a mix of assistance and monitoring. It is important to know whether it is the nature of the program, the assistance, or the supervision of the job search that is responsible for an improvement in the return to employment. For example, all the interventions listed in Meyer (1995) show a positive impact, but they all combine assistance and monitoring.

Van den Berg \& Van der Klaauw (2006) develop a model in which job seekers can look for work using an official channel as well as informal channels. They show that assistance and supervision of search along the official channel lead to a change in the overall search effort and to a substitution of the effort between channels. Job search programs lead to a global improvement of employment perspectives, although substitution between channels reduces their potential effects. On the other hand, monitoring policies may end up reducing the rate of exit if they force job seekers to increase their search efforts in a less productive channel. Van den Berg \& Van der Klaauw (2006) show that this is the case with monitoring programs that target job seekers who have a good chance of finding employment: At best, the programs are ineffective and can have negative consequences. On the other hand, when programs target job seekers whose chances are limited, they may lead to an improvement in the rate of exit toward employment.

Ashenfelter et al. (2005) present the results of a unique experiment that casts light on the above question, in which only monitoring of the search effort is reinforced. In that contribution, the authors run a randomized experiment in which interventions are specifically designed to address the aforementioned issue. The hypothesis being tested was that increasing supervision of the search effort accelerates the return to employment and reduces the amount of unemployment benefits paid out. The controversy is widely debated in the United States and elsewhere and is based on the idea that paying indemnities leads to a reduction in search efforts and to extended periods of unemployment. The authors studied a population of job seekers eligible for unemployment benefits. Their main variable was the 
amount of unemployment benefits received by the job seekers. Two systems were tested. The first consisted in verifying that the conditions for unemployment benefit eligibility were checked. The second consisted in reinforcing the surveillance of the search effort at the beginning of the period of unemployment. The experimental design consisted of assigning the eligible population to either a control group or a test group for which conditions of eligibility for unemployment benefits were checked. The members of the test group were then randomly assigned again to two separate groups: In one, the search efforts declared during the habitual appointment with the counselor were checked. The authors concentrate their analysis on the impacts on the return to employment and benefits paid out. They conclude, first of all, that verifying the conditions of unemployment benefit eligibility does not lead to a significant reduction in the benefits allocated. Secondly, they conclude that supervising the search effort has no impact on the benefits and the length of time they are paid out, despite a large sample, which would guarantee the possibility of detecting even a small effect.

\subsection{Details are important}

As mentioned in our review of the different types of programs, there is a great deal of heterogeneity in the way a general idea surrounding a program is implemented. Another key feature is that most programs are actually quite complicated. They impose many conditions that can in turn create a range of incentives for individuals. These incentives can in fact play a strong role in overall impact. They can account for a large share of impact along with the core idea of the program. The SSP for welfare recipients, analyzed by Card \& Hyslop (2005), is an example. The SSP has two distinct phases. The second phase, lasting 36 months, is usually seen as the core of the program. During this phase, participants receive an earnings bonus as long as they work at least 30 hours a week. There is, however, a qualification phase to become eligible for the second phase: Eligible welfare recipients have to obtain their first payment within the first year. The program had a significant impact on welfare participation rates, although it quickly faded after the 36-month phase ended. However, this impact is the result of both the bonus and the qualification incentives. A key result obtained in Card \& Hyslop (2005) is that half of the reduction seen at the peak of the welfare participation rate was due to the qualification incentive, meaning that just half was due to the incentive provided by the main idea of the program.

The analysis of the Job First program by Bitler et al. (2006) is another example. The Job First program is another supplement income program. As shown in Bitler et al. (2006), the subsidy scheme is quite complex and provides strong incentives when choosing hours of 
work. A simple static labor supply model clearly shows that impact on hours of work can be zero, positive, or negative, as can the impact on earnings and income. Using quantile treatment effects, the authors show that the mean impact of the program is small but that impacts at different quantiles are strong and can be either positive or negative. Moreover, the authors discuss the pattern of the impacts and find them to be broadly consistent with incentives provided by the subsidy scheme.

\subsection{The role of information on job market opportunities}

Several studies have illustrated the important role played by access to information in economic opportunities and employment outcomes, particularly in developing countries. The study by Jensen (2012) shows that making information available about the economic opportunities in some sectors in villages in India and proposing free job placement services have an impact on employment and on girls' thinking about future careers and marriage. Another study by Franklin (2015) shows that in Ethiopia, subsidizing the transportation costs of unemployed youth facilitates travel to inner cities where most information on available jobs can be found has a large impact. For young people who were the least excluded from the labor market, there was an improvement in both access to and stability of employment. For young people who were more excluded from the labor market, only impact on access to employment was noted. Other studies yield results that point in the same direction: Beam (2014) shows that in the Philippines subsidizing participation in job fairs has a large impact on employment, and Dammert et al. (2013) show that in Peru proposing jobs by telephone also has a significant impact on employment.

In developed countries, too, the role of information is central. But there is a focus on the difficulty for job seekers to analyze and use that information. Research in behavioral economics has shown that in general the available information is underexploited with regard to labor market perceptions. Job seekers may remain durably set in biased perceptions of their chances of finding a job and in less than optimal behavior. Babcock et al. (2012) discuss this point extensively. They suggest ways of improving the content of the programs by stressing the individualization of information and how job seekers may use it. They particularly insist on the need to innovate and experiment with the ways information is presented to job seekers, to allow them to overcome the obstacle represented by references to their previous situation and to shape their expectations based on a rational analysis of their chances rather than on a projection of their past situation. 


\subsection{Signaling, or gains in productivity for programs of employment subsidies}

One objective of subsidized job programs is that beneficial effects on short-term employment and income should be transformed into long-term employment. Such long-term effects are liable to occur through several channels. On one hand, job seekers targeted by the program are generally low-productivity workers quite excluded from the labor market. Providing them with access to a job thanks to a subsidy is expected to also provide them with some valuable gain in experience. The job seekers involved should see their productivity progress and attain levels that make a subsidy unnecessary. The gains may take the form of improvements in hard skills but also in behavioral skills linked to being placed in a work situation. ${ }^{19}$ This study involved young job seekers with little knowledge of the world of work and workers excluded from employment for a long period of time.

On the other hand, subsidized jobs may have a long-term impact if the obstacle to working is mainly connected to an asymmetry of information between job seekers and potential employers that translates into a fixed cost for hiring the job seekers targeted by the measure. Subsidy programs can, in that case, permit employers to evaluate the skills of potential job seekers whose lack of relevant experience makes the employer doubtful. Granting a subsidy, then, finances part of the set cost of hiring, which also includes the eventual costs of training as well as the risk inherent in hiring.

Nevertheless, we do not know if the impact of employment subsidy programs can be attributed to a signaling effect or to better productivity. One important piece of information is provided by Pallais (2014). She shows the importance of asymmetrical information in the labor market and the impact of signals on productivity in the hiring process. She carried out a randomized experiment in which some job seekers registered on an online work site and were chosen at random to be hired and evaluated individually. Information on the skills thus measured was revealed to some of the job seekers hired and evaluated, also randomly chosen. Results show, first, that being hired once improves further performance on the labor market and, second, that when information on skills is revealed, on average, performance improves even more. One important conclusion of this study is to show that, without intervention, the market generates too little information about workers and that much hiring that would be profitable for the community does not take place. Giving a person his or her first employment experience reveals information that brings the person closer to optimal outcomes.

\footnotetext{
${ }^{19}$ Acquiring soft skills when returning to work is often presented as one of the main mechanisms of subsidized employment. Some programs even associate training programs that give access to soft skills with subsidized jobs (see Groh et al. 2012).
} 
The study by Autor \& Houseman (2010) demonstrates the limits of the notion that having job experience is better than nothing and enables a sustainable trajectory toward social integration through employment. The authors show in particular that participants in the Work First program who had a real-world initial work experience through direct employment saw an improvement in their future situation, contrary to those whose first work experience was through a temp agency; worse still, the trends show that the results of the latter employment category deteriorate with time.

The general design of the programs--assistance, employment subsidies, and training--can be carried out in several ways and also in combination. Certain studies have tried to test the variants of programs to see which combination was best. ${ }^{20}$ Robins et al. (2008), for example, tested a variant of the SSP (SSP+), where extra income was combined with access to job search assistance. The experiment incorporated three groups: a control group, a group enrolled in the SSP, and a group in SSP+. Results showed that being an SSP+ beneficiary led to durable added value compared to the control group, which lasted 52 months. Over the same period, the added value of the "simple" SSP had disappeared.

\subsection{Additional unexpected effects}

Surprising effects have been observed in some programs, leaving the impression that behind the main mechanism at work, other effects may also be present and carry the day. One possible effect is stigmatization: Choosing a given population for a subsidy singles them out as being less productive and devalues their application. In a study based on a famous randomized evaluation in Ohio, Burtless (1985) showed that the impact of attributing a voucher was negative. He attributed that to a signal stigmatizing the beneficiaries.

Subsidized jobs are expected to mainly affect demand. Yet, some studies show that their main effect may be to affect supply. Galasso et al. (2004), in Argentina, as well as Levinsohn et al. (2014), in South Africa, find that a program that awards young people vouchers giving employers the right to claim a bonus has a positive impact. Nevertheless, the authors of both studies found no trace of any demand on the part of the firms to actually capitalize on the voucher. The authors of these studies interpret the phenomenon as being tantamount to a job offer: Those with vouchers (or their entourage) imagine they have better chances of accessing good jobs and that spurs them to increase their efforts to find a job.

\footnotetext{
${ }^{20}$ Hendra et al.'s (2010) demonstration project in the United States tested different combination alternatives aimed at furthering job retention and improving income levels. These attempts have not yielded, however, any conclusive information.
} 


\section{$9 \quad$ The market for ALMP}

\subsection{A weak demand}

Several studies suggest that the demand for program participation is rather weak. One factor reported in many studies is the low rate of entry into the programs when they are offered (see, e.g., Heckman et al. 2000). Behaghel et al. (2014) also report that only 50 percent of job seekers targeted by an enhanced counseling program decided to participate when it was offered. Decker et al. (2000) show that the demand for additional job search assistance by job seekers enrolled in a program is very slight even though its impact on gains is sizeable, in terms of income for job seekers and savings in unemployment benefits for the government.

Another indication of weak demand lies in the existence of ex ante effects. Some studies report that being assigned to a job search assistance program in fact encourages potential beneficiaries to exit unemployment in order to avoid participating in the program. In other words, being assigned to an assistance program is seen as a punishment. One of the first studies to document this was that of Black et al. (2003). They show that when facing the choice between a combination of unemployment benefits, job search assistance, and monitoring on the one hand and none of these on the other, many individuals prefer the latter, arguably out of a dislike for the monitoring component of the first option. Van den Berg et al. (2009) show that the perceived likelihood of being assigned to a training program has a negative impact on reservation wages and a positive impact on the efforts to find a job.

These findings can be explained by a job search model where individuals dislike participation or, in the case of monitoring, simply by the fact that monitoring reduces the value of being unemployed. They lead one to wonder about the actual value of job search assistance and its perceived value by job seekers. Spinnewijn (2015) uses survey data from the United States on the efforts to find a job, the perception of what one's chances are to find one, and the actual chances of finding one. He shows that job applicants highly overestimate their chances of finding employment. He also shows, on the basis of control variable regressions, that at the same time, job seekers underestimate the extent to which their chances of finding work depend on their search efforts. These results lead Spinnewijn (2015) to conclude that job seekers probably do not dispose of all the information that would allow them to make the right choices when looking for work and when considering enrollment in assistance programs.

Babcock et al. (2012) echo the importance of psychological traits and behavioral biases, stressing the importance of the latter. They also stress the role of the preference for the 
present and its impact on the job search, and the tendency to procrastinate caused by overrating the hic et nunc. The fact that psychological characteristics play an important part in a job seeker's behavior has been well documented. DellaVigna \& Paserman (2005), for example, show that the more impatient a job seeker is, the less effective the search is, and the less likely he or she is to find employment. Caliendo et al. (2015) show that job seekers with a high locus of control, that is, those who think their destiny is determined by their own acts rather than by external factors, also demonstrate more energetic job-search behavior and have a higher reservation wage. The experimental program by Miller et al. (2012) seeks to simplify the social services and, in particular, training programs and possibilities for financing them, as well as make them more directly applicable to potential beneficiaries. Results show a rise in take-up for training and transfer revenues. Other interventions seek to compensate for weak demand by creating incentives to participate. Aeberhardt et al. (2015) in particular show that attributing a transfer on the condition that a beneficiary remain enrolled in a career guidance program had a large impact in the sense that youth remained in the program. However, the impact on their actual active participation, including participation in training and other demanding, productivity-enhancing programs, is small.

\subsection{Offering the services of ALMPs}

In many countries, ALMP services are offered by the private sector, whereas the public sector plays only a very secondary role. W. Lee (2009) explains how in the United States, the creation of the public service for employment was introduced to discipline the job placement market and chase agencies proposing low-quality services from the market. In European countries, the situation is generally more mitigated, with the coexistence of an historically powerful public service for employment, with private operators securing the right to serve some markets through public tenders. Several recent studies have dealt with the question of the relative effectiveness of assistance programs offered by the private sector and those offered by the public sector.

Behaghel et al. (2014) carried out a randomized evaluation in which three cohorts were randomly created; reinforced assistance services in the private sector were proposed to one cohort, the same services in the public sector to the second, and standard public services to the third. Results clearly showed that assistance offered by the public service is much more effective than that offered by the private sector. After six months, the return to employment improved at a rate of 9.1 with public sector assistance versus a rate of 3.8 in the private sector. In comparison, there was an average rate of return to employment after six months of 
approximately $20 \%$ for standard assistance. The authors explain the difference partly by the incentives given to private structures in contracts setting the conditions for their remuneration and partly by mastering job search assistance technology. ${ }^{21}$

\section{Conclusions}

The general outlook for ALMPs is rather grim. On the whole, evaluations have not shown these programs to be particularly effective. With regard to the difficulties of entering the job market, and considering the amount of effort that has gone into improving the process, the few positive results obtained in terms of employment seem meager indeed. In addition, many recent assessments have been unable to implement cost-benefit evaluations. Not only do the ALMPs seem less effective than might have been expected, but we do not really know if these programs are in fact an expense rather than a gain. Also, our knowledge about how ALMPs impact other outcomes such as health, family, or criminality is very spotty.

The possible existence of equilibrium effects on the efficiency of the programs seems quite real. Several recent studies show that improvements for beneficiaries are often achieved to the detriment of nonbeneficiaries. One might be tempted to conclude that ALMPs are mitigating inequalities in the labor market rather than providing an overall solution to the problem of unemployment.

That many studies reveal diversified results is grounds for hope: For some subpopulations, the effects are more marked than for others. Furthermore, not a lot is known to date about the effects of assignment rules for the target population and the underlying mechanisms. In this sense, there is a scope for new randomized controlled trials focusing on those issues. This also applies to the assessment of policies for socially excluded nonemployed youth who are at a large distance from the regular labor market and policies for individuals who are illinformed about their labor market conditions.

Designing ALMPs that achieve their goal of unemployment reduction remains a challenge. There is a need to identify how unemployed people, firms, and those producing and offering ALMP services behave and are incentivized by features of ALMPs.

\footnotetext{
${ }^{21}$ Krug \& Stephan (2013) and Laun \& Thoursie (2014) discuss other randomized evaluations of public/private job search assistance offers.
} 


\section{References}

Abbring JH, van den Berg GJ. 2003. The nonparametric identification of treatment effects in duration models. Econometrica 71(5):1491-517

Abbring JH, van den Berg GJ. 2005. Social experiments and instrumental variables with duration outcomes. Working paper 2005:11, IFAU (Institute for Evaluation of Labour Market and Education Policy), Uppsala, Sweden

Aeberhardt R, Chiod V, Crépon B, Gain M, Vicard A. 2015. The demand for employability investments: evidence from a youth conditional cash transfer program in France. Working Paper, Center for Research in Economics and Statistics, Malakoff, France

Albrecht J, van den Berg G, Vroman S. 2009. The aggregate labor market effects of the Swedish Knowledge Lift program. Review of Economic Dynamics 12(1):129-46

Ashenfelter O, Ashmore D, Deschenes O. 2005. Do unemployment insurance recipients actively seek work? Evidence from randomized trials in four U.S. states. Journal of Econometrics 125(1-2):53-75

Attanasio O, Kugler A, Meghir C. 2011. Subsidizing vocational training for disadvantaged youth in Colombia: evidence from a randomized trial. American Economic Journal: Applied Economics 3(3):188-220

Attanasio O, Guarín A, Medina C, Meghir C 2015. Long Term Impacts of Vouchers for Vocational Training: Experimental Evidence for Colombia. Working paper 21390 National Bureau of Economic Research

Autor DH, Houseman SN. 2010. Do temporary-help jobs improve labor market outcomes for low-skilled workers? Evidence from "Work First.” American Economic Journal: Applied Economics 2(3):96-128

Babcock L, Congdon W, Katz L, Mullainathan S. 2012. Notes on behavioral economics and labor market policy. IZA Journal of Labor Policy 1(1):1-14

Beam E. 2014. Incomplete information in job search: evidence from a field experiment in the Philippines. Working Paper, Department of Economics, National University of Singapore

Behaghel L, Crépon B, Gurgand M. 2014. Private and public provision of counseling to job seekers: evidence from a large controlled experiment. American Economic Journal: Applied Economics 6(4):142-74 
Behncke S, Frölich M, Lechner M. 2007. Targeting labour market programmes: results from a randomized experiment. Working Paper 3085, IZA (Institute for the Study of Labor), Bonn, Germany

Bell SH, Orr LL. 1994. Is subsidized employment cost effective for welfare recipients? Experimental evidence from seven state demonstrations. Journal of Human Resources 29(1):42-61

Bergemann AH, van den Berg GJ. 2008. Active labor market policy effects for women in Europe: a survey. Annals of Economics and Statistics 91/92:377-99

Bhattacharya D, Dupas P. 2012. Inferring welfare maximizing treatment assignment under budget constraints. Journal of Econometrics. 167(1):168-96

Bitler M, Gelbach J, Hoynes H. 2006. What mean impacts miss: distributional effects of welfare reform experiments. American Economic Review 96:988-1012

Björklund A, Clark M, Edin PA, Fredriksson P, Krueger A. 2005. The Market Comes to Education--An Evaluation of Sweden's Surprising School Reforms. New York: Russell Sage

Black DA, Smith JA, Berger MC, Noel BJ. 2003. Is the threat of reemployment services more effective than the services themselves? Evidence from random assignment in the UI system. American Economic Review 93(4):1313-27

Blasco S, Rosholm M. 2011. The impact of active labour market policy on postunemployment outcomes: evidence from a social experiment in Denmark. Working Paper 5631, IZA (Institute for the Study of Labor), Bonn, Germany

Bloom D. 2010. Transitional jobs: background, program models, and evaluation evidence. MDRC, New York

Bloom D, Michalopoulos C. 2001. How welfare and work policies affect employment and income: a synthesis of research. MDRC, New York

Bloom HS, Orr LL, Bell SH, Cave G, Doolittle F, et al. 1997. The benefits and costs of JTPA title II-A programs: key findings from the National Job Training Partnership Act study. Journal of Human Resources 32(3):549-76 
Blundell R, Dias MC, Meghir C, Reenen JV. 2004. Evaluating the employment impact of a mandatory job search program. Journal of the European Economic Association 2(4):569_ 606

Brodaty T, Crépon B, Fougere D. 2002. Using matching estimators to evaluate alternative youth employment programs: evidence from France, 1986-1988. In Econometric Evaluation of Labour Market Policies, ed. M. Lechner, F Pfeiffer, pp. 85-123. Berlin: Springer-Verlag

Burtless G. 1985. Are targeted wage subsidies harmful? Evidence from a wage voucher experiment. Industrial and Labor Relations Review 39(1):105-14

Butler D, Alson J, Bloom D, Deitch V, Hill A, et al. 2012. What strategies work for the hardto-employ? Final results of the hard-to-employ demonstration and evaluation project and selected sites from the employment retention and advancement project. MDRC, New York

Cahuc P, Le Barbanchon T. 2010. Labor market policy evaluation in equilibrium: some lessons of the job search and matching model. Labour Economics 17(1):196-205

Caliendo M, Cobb-Clark DA, Uhlendorff A. 2015. Locus of control and job search strategies. Review of Economics and Statistics 97(1):88-103

Caliendo M, Hujer R, Thomsen S. 2005. The employment effects of job creation schemes in Germany: a microeconometric evaluation. Working Paper 1512, IZA (Institute for the Study of Labor), Bonn, Germany

Calmfors L. 1994. Active labour market policy and unemployment - a framework for the analysis of crucial design features. OECD Journal: Economic Studies. 22:7-47

Carcillo S, Grubb D. 2006. From inactivity to work: the role of active labour market policies, social employment and migration. Working Paper 36, OECD (Organisation for Economic Co-operation and Development), Paris

Card D, Hyslop DR. 2005. Estimating the effects of a time-limited earnings subsidy for welfare-leavers. Econometrica 73(6):1723-70

Card D, Ibarraran P, Regalia F, Rosas-Shady D, Soares Y. 2011. The labor market impacts of youth training in the Dominican Republic. Journal of Labor Economics 29(2):267-300

Card D, Kluve J, Weber A. 2010. Active labour market policy evaluations: a meta-analysis. Economic Journal 120(548):F452-77 
Card D, Kluve J, Weber A. 2015. What works? A meta analysis of recent active labor market program evaluations. Discussion Paper 9236, IZA (Institute for the Study of Labor), Bonn, Germany

Cave G, Bos H, Doolittle F, Toussaint C. 1993. JOBSTART: final report on a program for school dropouts. MDRC, New York

Couch KA. 1992. New evidence on the long-term effects of employment training programs. Journal of Labor Economics 10(4):380-88

Crépon B, Dejemeppe M, Gurgand M. 2005. Counseling the unemployed: Does it lower unemployment duration and recurrence? Discussion Paper 1796, IZA (Institute for the Study of Labor), Bonn, Germany

Crépon B, Duflo E, Gurgand M, Rathelot R, Zamora P. 2013. Do labor market policies have displacement effects? Evidence from a clustered randomized experiment. Quarterly Journal of Economics 128(2):531-80

Crépon B, Ferracci M, Jolivet G, van den Berg GJ. 2009. Active labor market policy effects in a dynamic setting. Journal of the European Economic Association 7(2-3):595-605

Dammert AC, Galdo J, Galdo V. 2013. Digital labor-market intermediation and job expectations: evidence from a field experiment. Economics Letters 120(1):112-16

Davidson C, Woodbury SA. 1993. The displacement effect of reemployment bonus programs. Journal of Labor Economics 11(4):575-605

Decker P, Olsen R, Freeman L, Klepinger D. 2000. Assisting unemployment insurance claimants: the long-term impacts of the job search assistance demonstration. Project Report 8170-700, Mathematica Policy Research, Princeton, NJ, USA

DellaVigna S, Paserman MD. 2005. Job search and impatience. Journal of Labor Economics 23(3):527-88

Dhaliwal I, Duflo E, Glennerster R, Tulloch C. 2011. Comparative cost-effectiveness analysis to inform policy in developing countries: a general framework with applications for education. In Education Policy in Developing Countries, ed. P. Glewwe. Chicago: University of Chicago Press

Djebbari H, Smith J. 2008. Heterogeneous impacts in PROGRESA. Journal of Econometrics 145:64-80 
Dolton P, O’Neill D. 2002. The long-run effects of unemployment monitoring and worksearch programs: experimental evidence from the United Kingdom. Journal of Labor Economics 20(2):381-403

Eberts RW, O’Leary CJ, Wandner SA, eds. 2002. Targeting Employment Services. Kalamazoo, MI: Upjohn Institute Press

Eissa N, Liebman JB. 1996. Labor supply response to the earned income tax credit. Quarterly Journal of Economics 111(2):605-37

Fay RG. 1996. Enhancing the effectiveness of active labour market policies: evidence from programme evaluations in OECD countries. Working Paper 18, OECD (Organisation for Economic Co-operation and Development), Paris

Ferracci M, Jolivet G, van den Berg GJ. 2014. Evidence of treatment spillovers within markets. Review of Economics and Statistics 96(5):812-23

Forslund A, Fredriksson P, Vikström J. 2011. What active labor market policy works in a recession? Nordic Economic Policy Review 1:171-201

Forslund A, Krueger AB. 1997. An evaluation of the Swedish active labor market policy: new and received wisdom. NBER Working Paper 4802

Franklin S. 2015. Location, search costs and youth unemployment: a randomized trial of transport subsidies in Ethiopia. Working Paper WPS/2015-11, Centre for the Study of African Economies, University of Oxford, UK

Friedlander D. 1988. Subgroup impacts and performance indicators for selected welfare employment programs. MDRC, New York

Frölich M. 2008. Statistical treatment choice: an application to active labor market programs. Journal of the American Statistical Association 103(482):547-58

Frölich M, Lechner M, Steiger H. 2003. Statistically assisted programme selection-international experiences and potential benefits for Switzerland. Swiss Journal of Economics and Statistics 139(III):311-31

Galasso E, Ravallion M, Salvia A. 2004. Assisting the transition from workfare to work: a randomized experiment. Industrial and Labor Relations Review 58(1):128-42 
Gerfin M, Lechner M, Steiger H. 2005. Does subsidised temporary employment get the unemployed back to work? An econometric analysis of two different schemes. Labour Economics 12(6):807-35

Groh M, Krishnan N, McKenzie D, Vishwanath T. 2012. Soft skills or hard cash? The impact of training and wage subsidy programs on female youth employment in Jordan. Working Paper 6141, World Bank, Washington, DC, USA

Grubb D, Puymoyen A. 2008. Long time series for public expenditure on labour market programmes, OECD social, employment and migration. Work. Pap. 73, OECD (Organisation for Economic Co-operation and Development), Paris

Ham JC, LaLonde RJ. 1996. The effect of sample selection and initial conditions in duration models: evidence from experimental data on training. Econometrica 64:175-205

Heckman JJ, Hohmann N, Smith J, Khoo M. 2000. Substitution and dropout bias in social experiments: a study of an influential social experiment. Quarterly Journal of Economics $651-94$

Heckman JJ, LaLonde RJ, Smith JA. 1999. The economics and econometrics of active labor market programs. Handbook of Labor Economics 3:1865-2097

Heckman JJ, Lochner L, Taber C. 1998. General equilibrium treatment effects: a study of tuition policy. American Economic Review 88:381-86

Heckman JJ, Smith J, Clements N. 1997. Making the most out of programme evaluations and social experiments: accounting for heterogeneity in programme impacts. Review of Economic Studies 64(4):487-535

Hendra R, Dillman K-N, Hamilton G, Lundquist E, Martinson K, et al. 2010. How effective are different approaches aiming to increase employment retention and advancement? Final impacts for twelve models. MDRC, New York

Hirshleifer S, McKenzie D, Almeida R, Ridao-Cano C. 2014. The impact of vocational training for the unemployed: experimental evidence from Turkey. Economic Journal In press. doi: 10.1111/ecoj.12211

Hollister RG, Kemper P, Maynard RA. 1984. The National Supported Work Demonstration. Madison: University of Wisconsin Press 
Jensen R. 2012. Do labor market opportunities affect young women's work and family decisions? Experimental evidence from India. Quarterly Journal of Economics 127(2):753-92

Katz LF. 1998. Wage subsidies for the disadvantaged. In Generating Jobs: How to Increase Demand for Less-Skilled Workers, ed. RB Freeman, P Gottschalk, pp. 21-53. New York: Russell Sage

Krug G, Stephan G. 2013. Is the contracting-out of intensive placement services more effective than provision by the PES? Evidence from a randomized field experiment. Working Paper 7403, IZA (Institute for the Study of Labor), Bonn, Germany.

Kugler A, Kugler M, Saavedra J, Prada L. O. H. (2015). Long-term direct and spillover effects of job training: Experimental evidence from Colombia, Working Paper 21607, National Bureau of Economic Research.

Laun L, Thoursie PS. 2014. Does privatisation of vocational rehabilitation improve labour market opportunities? Evidence from a field experiment in Sweden. Journal of Health Economics 34:59-72

Lechner M, Miquel R, Wunsch C. 2011. Long-run effects of public sector sponsored training in West Germany. Journal of the European Economic Association 9(4):742-84

Lechner M, Smith J. 2007. What is the value added by caseworkers? Labour Economics 14(2):135-51

Lee DS. 2009. Training, wages, and sample selection: estimating sharp bounds on treatment effects. Review of Economic Studies 76(3):1071-102

Lee W. 2009. Private deception and the rise of public employment offices in the United States, 1890-1930. In Studies of Labor Market Intermediation, ed. DH Autor, pp. 155-82. Chicago: University of Chicago Press

Levinsohn J, Rankin N, Roberts G, Schöer V. 2014. Wage subsidies and youth employment in South Africa: evidence from a randomised control trial. Working Paper 02/14, Department of Economics, Stellenbosch University, South Africa

Lise J, Seitz S, Smith J. 2015. Evaluating search and matching models using experimental data. IZA Journal of Labor Economics 4:16 
Manski CF. 2004. Statistical treatment rules for heterogeneous populations. Econometrica 72(4):1221-46

Martin JP, Grubb D. 2001. What works and for whom: a review of OECD countries' experiences with active labour market policies. Swedish Economic Policy Review 8:9-56

Meyer BD. 1995. Lessons from the US unemployment insurance experiments. Journal of Economic Literature 33(1):91-131

Michalopoulos C. 2004. What works best for whom? Effects of welfare and work policies by subgroup. MDRC, New York

Michalopoulos C, Robins PK, Card D. 2005. When financial work incentives pay for themselves: evidence from a randomized social experiment for welfare recipients. Journal of Public Economics 89(1):5-29

Michalopoulos C, Schwartz C. 2001. What works best for whom? Impacts of 20 welfare-towork programs by subgroup. MDRC, New York

Millenky M, Bloom D, Muller-Ravett S, Broadus J. 2011. Staying on course: three-year results of the National Guard Youth ChalleNGe evaluation. MDRC, New York

Miller C, van Dok M, Tessler BL, Pennington A. 2012. Strategies to help low-wage workers advance: implementation and final impacts of the Work Advancement and Support Center (WASC) demonstration. MDRC, New York

Moffitt R. 2002. Policy interventions, low-level equilibria, and social interactions. In Social Dynamics, ed. S Durlauf, P Young, pp. 45-82. Cambridge, MA: MIT Press

OECD (Organisation for Economic Co-operation and Development). 2013. Employment Outlook 2013. Paris: OECD

Pallais A. 2014. Inefficient hiring in entry-level labor markets. American Economic Review 104(11):3565-99

Robins PK, Michalopoulos C, Foley K. 2008. Are two carrots better than one? The effects of adding employment services to financial incentive programs for welfare recipients. Industrial and Labor Relations Review 61(3):410-23

Schochet PZ, Burghardt J, McConnell S. 2006. National Job Corps study and longer-term follow-up study: impact and benefit-cost findings using survey and summary earnings records data. Project Report 6095-300, Mathematica Policy Research, Princeton, NJ, USA 
Schochet PZ, Burghardt J, McConnell S. 2008. Does Job Corps work? Impact findings from the National Job Corps study. American Economic Review 98:1864-86

Spinnewijn J. 2015. Unemployed but optimistic: optimal insurance design with biased beliefs. Journal of the European Economic Association 13(1):130-67

van den Berg GJ, Bergemann AH, Caliendo M. 2009. The effect of active labor market programs on not-yet treated unemployed individuals. Journal of the European Economic Association 7(2-3):606-16

van den Berg GJ, van der Klaauw B. 2006. Counseling and monitoring of unemployed workers: theory and evidence from a controlled social experiment. International Economic Review 47(3):895-936

van den Berg GJ, van der Klaauw B. 2013. Structural empirical evaluation of job search monitoring. Working Paper 7740, IZA (Institute for the Study of Labor), Bonn, Germany

van den Berg GJ, van der Klaauw B, van Ours JC. 2004. Punitive sanctions and the transition rate from welfare to work. Journal of Labor Economics 22:211-41

van den Berg GJ, Vikström J. 2014. Monitoring job offer decisions, punishments, exit to work, and job quality. Scandinavian Journal of Economics 116:284-334

Vikström J. 2014. IPW estimation and related estimators for evaluation of active labor market policies in a dynamic setting. Working paper 2014:1, IFAU (Institute for Evaluation of Labor Market and Education Policy), Uppsala, Sweden

Woodbury SA, Spiegelman RG. 1987. Bonuses to workers and employers to reduce unemployment: randomized trials in Illinois. American Economic Review 77(4):513-30 


\section{Appendix}

Table 1 Public expenditure on and participant stocks in ALMPs in 2011

\begin{tabular}{|c|c|c|c|}
\hline \multirow[t]{2}{*}{ Country } & \multicolumn{2}{|c|}{ Public expenditure as a percentage of GDP } & \multirow{2}{*}{$\begin{array}{c}\text { Participant stocks as a percentage of the labor force } \\
\text { Active program measures (1-7) } \\
\text { Categories } 2-7 \text { only }\end{array}$} \\
\hline & Active program measures (1-7) & $\begin{array}{l}\text { Active program measures }(1-7) \\
\text { Categories } 2-7 \text { only }\end{array}$ & \\
\hline Australia & 0.29 & 0.14 & 2.26 \\
\hline Austria & 0.75 & 0.57 & 3.59 \\
\hline Belgium & 1.59 & 1.38 & 12.54 \\
\hline Canada & 0.26 & 0.15 & 0.37 \\
\hline Chile & 0.1 & 0.07 & - \\
\hline Czech Republic & 0.27 & 0.18 & 1.11 \\
\hline Denmark & 2.26 & 1.59 & 6.57 \\
\hline Estonia & 0.23 & 0.15 & 0.87 \\
\hline Finland & 1.02 & 0.85 & 4.41 \\
\hline France & 0.93 & 0.68 & 5.11 \\
\hline Germany & 0.79 & 0.45 & 2.85 \\
\hline Hungary & 0.36 & 0.35 & 3.82 \\
\hline Israel & 0.18 & 0.16 & 4.52 \\
\hline Italy & 0.41 & 0.31 & 4.85 \\
\hline Japan & 0.27 & 0.21 & - \\
\hline Korea & 0.33 & 0.31 & - \\
\hline Luxembourg & 0.56 & 0.51 & 7.73 \\
\hline Mexico & 0.01 & 0.01 & - \\
\hline Netherlands & 1.11 & 0.7 & 4.22 \\
\hline New Zealand & 0.27 & 0.18 & 1.65 \\
\hline Norway & - & 0.45 & 2.27 \\
\hline Poland & 0.42 & 0.33 & 3.27 \\
\hline Portugal & 0.59 & 0.46 & 3.37 \\
\hline Slovak Republic & 0.3 & 0.22 & 2.7 \\
\hline Slovenia & 0.36 & 0.25 & 2.03 \\
\hline Spain & 0.88 & 0.73 & 11.44 \\
\hline Sweden & 1.09 & 0.8 & 3.75 \\
\hline Switzerland & 0.59 & 0.47 & 1.16 \\
\hline United States & 0.14 & 0.1 & - \\
\hline OECD countries & 0.58 & 0.44 & 4.02 \\
\hline
\end{tabular}

${ }^{a}$ OECD Categories 2-7 contain what we call the productivity ALMPs. Category 1 contains what we call the matching ALMPs but also the operational costs of employment offices and the costs of monitoring benefit recipients. Data on Greece, Ireland, and the United Kingdom are unavailable.

Abbreviations: ALMPs = active labor market policies; GDP = gross domestic product; OECD = Organisation for Economic Co-Operation and Development. 